\title{
Histone deacetylase inhibitors in the treatment for multiple myeloma
}

\author{
Teru Hideshima $\cdot$ Kenneth C. Anderson
}

Received: 27 December 2012/ Accepted: 6 February 2013/Published online: 10 March 2013

(c) The Japanese Society of Hematology 2013

\begin{abstract}
Histone lysine acetylation is regulated by both histone deacetylases (HDACs) and histone acetyl transferases. Inhibition of deacetylases induces hyperacetylate of target proteins and has a crucial role in the epigenetic regulation of gene expression mediating cell survival and proliferation. Therefore, HDAC inhibitors have emerged as novel therapeutic agents for cancers, including multiple myeloma (MM). Recent studies revealed that HDAC inhibitors trigger hyperacetylation of not only histones, but also non-histone proteins regulating cell growth and survival, revealing the complexity of mechanism of action of HDAC inhibitors. Many HDAC inhibitors have already shown significant anti-MM activities in preclinical studies and are under evaluation in clinical trials.
\end{abstract}

Keywords Multiple myeloma - Histone deacetylase $($ HDAC $) \cdot$ HDAC inhibitor · Proteasome inhibitor

\section{Introduction}

Histones are the major protein components of chromatin and have been found in the nuclei of all eukaryotic cells, where they are complexed with DNA to form the repeating structure of chromatin. Histones are relatively low molecular weight and are grouped into five major classes; two

\footnotetext{
T. Hideshima $(\bowtie) \cdot$ K. C. Anderson

Department of Medical Oncology, Jerome Lipper Multiple

Myeloma Center, Dana-Farber Cancer Institute

and Harvard Medical School, 450 Brookline Avenue,

Boston, MA 02215, USA

e-mail: teru_hideshima@dfci.harvard.edu

K. C. Anderson

e-mail: kennth_anderson@dfci.harvard.edu
}

copies of H2A, one copy of H2B, H3 and H4. Each histone has different lysine $(\mathrm{K})$ residues, and then their acetylation status is regulated by two key enzymes, histone acetyltransferase (HAT) and histone deacetylase (HDAC). For example, histone $\mathrm{H} 3$ tail has K9, K14, K18, K23, K56 which can be hyperacetylated [1].

Histone acetylation is regulated by 18 HDACs, which are divided into 4 classes: class I (HDAC 1, 2, 3, and 8), class IIa (HDAC 4, 5, 7, and 9), class IIb (HDAC 6 and 10), class III (SIRT family), and class IV (HDAC11) (Table 1). Class I and IV HDACs are localized in the nucleus, whereas class II HDACs can shuttle between the nucleus and the cytoplasm with 14-3-3 protein [2,3]. HDACs catalyze the removal of the acetyl modification on lysine residues of proteins, including the core nucleosomal histones H2A, H2B, H3, and H4. During transcription, the transcription factors bind to their specific binding site in the promoter region of DNA. When the DNA is in compact form, it is difficult for these proteins to access DNA, thereby limiting transcription. In contrast, when DNA is bundled into chromosomes, histones play a major role in restricting the binding of transcription factors to DNA. Importantly, the acetylation status of the amino-terminus of histones is crucial for their binding to DNA. Therefore, hyperacetylation of histones allows transcription to occur, whereas deacetylation of histones prevents transcription; HDAC inhibitors therefore trigger transcription.

Importantly, recent studies have identified more than 3000 lysine acetylation sites on 1750 proteins, and also quantified acetylation changes in response to the nonselective deacetylase inhibitor suberoylanilide hydroxamic acid (SAHA) and class I-selective deacetylase inhibitor entinostat (MS-275) [4]. Lysine acetylation preferentially targets large macromolecular complexes involved in diverse cellular processes, such as chromatin remodeling, cell cycle progression, splicing, nuclear transport, and actin 
Table 1 Classification of histone deacetylase

\begin{tabular}{llll}
\hline Class I & Class II & Class III $^{\mathrm{a}}$ & Class IV \\
\hline HDAC1 & HDAC4 & SIRT1 & HDAC11 \\
HDAC2 & HDAC5 & SIRT2 & \\
HDAC3 & HDAC6 & SIRT3 & \\
HDAC8 & HDAC7 & SIRT4 & \\
& HDAC9 & SIRT5 & \\
& HDAC10 & SIRT6 & \\
& & SIRT7 & \\
\hline
\end{tabular}

${ }^{a}$ Class III HDACs are homologs of the yeast protein Sir2

nucleation. However, which HDAC isoform selectively deacetylates specific histones or non-histone proteins has not yet been elucidated.

\section{HDAC inhibitors}

A large number of structurally diverse HDAC inhibitors have been generated from natural sources or synthetically developed. HDAC inhibitors are divided into six classes based on their chemical structure. These classes are: shortchain fatty acid, hydroxamate, benzamide, cyclic tetrapeptide, electrophilic ketone and others (Table 2). Although currently developed HDAC inhibitors nonselectively target HDACs, the inhibitory effect on each HDAC by these agents varies [4] (Fig 1). We will discuss selected MM-relevant HDAC inhibitors in this section.

Non-selective HDAC inhibitor

\section{Vorinostat (suberoylanilide hydroxamic acid, SAHA)}

Vorinostat inhibits class I and II HDAC activity and its anti-tumor activities has been extensively studied in many

Table 2 Selected HDAC inhibitors by classes

\begin{tabular}{ll}
\hline Short-chain fatty acids & Cyclic peptides \\
Sodium butyrate & Trapoxin \\
Phenylbutyrate & Apicidin \\
An-9 & Romidepsin (FK-228) \\
Valproic acid & \\
Hydroxamic acids & Benzamides \\
Trichostatin A & Entinostat (MS-275) \\
HMBA & \\
Vorinostat (SAHA) & \\
Pyroxamide & \\
LAQ824 & \\
Panobinostat (LBH589) & \\
ACY-1215 & \\
\hline
\end{tabular}

Differential HDAC Inhibition Profiling of HDAC Inhibitors

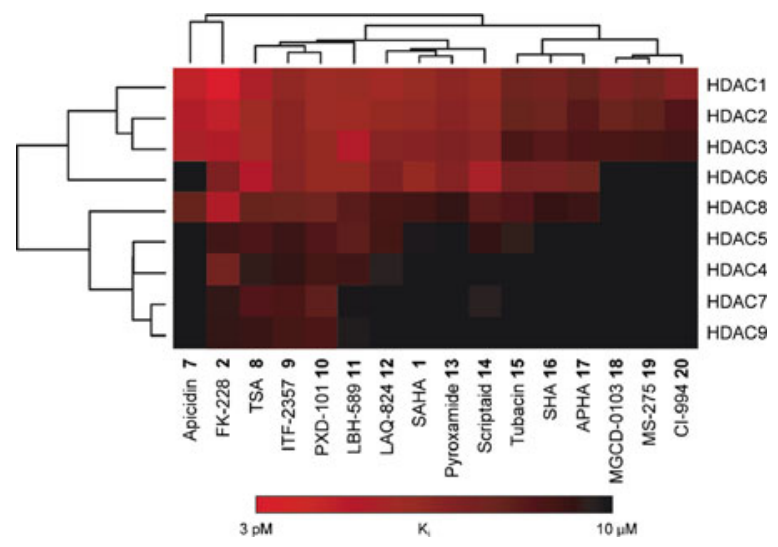

Fig. 1 Differential inhibitory effect of non-selective HDAC inhibitors against HDAC isoforms (adopted from [4])

types of cancers. Vorinostat directly interacts with the catalytic site of HDACs and inhibits their enzymatic activity. Inhibition of HDAC activity by vorinostat results in alteration of gene expression in various cancer cell lines, including MM [5]. Vorinostat blocks HDAC activity in cancer cell lines in vitro with IC50s of high $\mathrm{nM}$ to low $\mu \mathrm{M}$ range.

MVP-LAQ824 (LAQ824)

LAQ824 is a hydroxamic acid and inhibits class I and II HDAC activity. LAQ824 blocks HDAC activity in cancer cell lines in vitro with IC50s of 10-150 nM ranges, indicating that anti-proliferative potency of LAQ824 is up to 200 -fold higher than that of vorinostat [6, 7]. In MM, LAQ824 induces apoptosis in most cell lines and primary tumor cells from patients at IC50 of $100 \mathrm{nM}$ at $24 \mathrm{~h}$ [8].

\section{Panobinostat (LBH589)}

Panobinostat is also a hydroxamic acid and blocks class I and II HDAC activity. However, its inhibitory effect on class I HDAC is more potent than class II HDAC (i.e., HDAC6) compared to vorinostat. Panobinostat has been studied in various malignancies as a single agent, as well as combined with other anticancer agents [9-12]. In MM, IC50 of panobinostat is $20-80 \mathrm{nM}$ in most cell lines, including those resistant to conventional therapeutic agents $[13,14]$.

\section{Belinostat (PXD101)}

Belinostat is a hydroxamate class HDAC inhibitor [15] which demonstrates broad anti-tumor activity in vitro and in vivo [16]. Belinostat inhibits various types of cancer cell 
growth, with IC50 from 0.2 to $0.7 \mu \mathrm{M}$. Belinostat has antiproliferative activity in MM cell lines, and shows additive and/or synergistic effects with conventional agents used in MM. Belinostat is being tested as monotherapy and also in combination with standard agents for treatment of MM.

Class I HDAC inhibitor

\section{Entinostat (MS-275)}

Entinostat is a benzamide class HDAC inhibitor and blocks class I HDAC activity. Entinostat shows anti-tumor activity in various types of cancers in vitro, with IC50 of between high $\mathrm{nM}$ to low $\mu \mathrm{M}$ range. Like other HDAC inhibitors, entinostat induces caspase-dependent apoptosis [17].

\section{Romidepsine (FR901228, FK228)}

Romidepsine is a natural (isolated from Chromobacterium violaceum) or synthetic compound with sequences of amino and hydroxy carboxylic acid residues. It inhibits HDAC1 and HDAC2 with IC50 of 1.6 and $3.9 \mathrm{nM}$ by noncell base and cell-based assays, respectively [18-21]. In MM, romidepsine induces apoptosis both in cell lines and primary tumor cells from patients, associated with downregulation of Bcl-2, BCL-xL and Mcl-1 expression [22].

\section{HDAC6 inhibitor}

\section{ACY-1215}

ACY-1215 is the first in class HDAC6-selective hydroxamate HDAC inhibitor [23]. Previous studies have characterized the aggresome as an alternative system to the proteasome for degradation of polyubiquitinated misfolded/unfolded proteins [24]. The aggresome pathway therefore likely provides a novel system for delivery of aggregated proteins from cytoplasm to lysosomes for degradation [25]. In this aggresomal protein degradation pathway HDAC6 has an essential role, since it can bind both polyubiquitinated proteins and dynein motors, thereby acting to recruit protein cargo to dynein motors for transport to aggresomes $[24,26]$.

\section{Other HDAC inhibitors}

KD5170 is non-hydroxamate, orally bioavailable HDAC inhibitor, which significantly inhibits osteoclast formation at low $\mu \mathrm{M}$ range and also triggers apoptosis in $\mathrm{MM}$ cells [27]. Suberoyl-3-aminopyridineamide hydroxamic acid (pyroxamide) belongs to the hydroxamate class and has demonstrated its anti-tumor activities against prostate cancer and rhabdomyosarcoma in vitro. CI-994 is a substituted benzamide derivative that has demonstrated significant anti-tumor activity in vitro and in vivo in a broad spectrum of tumor models [28, 29]. Although CI-994 ( $N$-acetyl-dinaline) is a pan HDAC inhibitor, its specificity and molecular mechanisms whereby it induces cytotoxicity in tumor cells remains unclear.

\section{Preclinical activities of HDAC inhibitors in MM}

Mechanisms of action whereby HDAC inhibitors trigger anti-MM activities have not yet been fully characterized. Inhibition of histone deacetylation primarily triggers gene transcription, and therefore HDAC inhibitors induce transcription of both positive and negative regulators of cell proliferation and/or survival. Specifically, the cytotoxicity/ growth inhibition induced by HDAC inhibitors is the result of relative upregulation of pro-apoptotic (growth suppressive) factors. Importantly, recent studies identify a number of lysine residues in non-histone proteins involved in modulating gene expression, DNA replication/repair, cell cycle progression, cytoskeletal reorganization, and protein chaperone activity [30]. These findings suggest further complex mechanisms of action of anti-MM tumor activities of HDAC inhibitors.

In general, the IC50 of MM cell cytotoxicity varies among each HDAC inhibitors from the $\mathrm{nM}$ to $\mu \mathrm{M}$ range due not only to their cell permeability and/or pharmacokinetics/pharmacodynamics, but also to differential inhibitory effects against each HDAC isoforms HDAC1HDAC11. Although, to date, the specific target proteins of each HDAC isoforms have not yet been elucidated, there is no significant difference on mechanism of action triggering MM cell growth inhibition by different non-selective HDAC inhibitors in preclinical studies (Fig. 2). We will therefore focus on vorinostat to describe non-selective HDAC inhibitor-induced anti-MM activities.

In MM, vorinostat induces upregulation of $\mathrm{p} 21^{\mathrm{WAF} 1}$, a hallmark of HDAC inhibition, and induces p53 protein expression as well as dephosphorylates $\mathrm{Rb}$, followed by apoptosis. Importantly, upregulation of $\mathrm{p} 21^{\mathrm{WAF} 1}$ occurs prior to $\mathrm{p} 53$ induction, suggesting that $\mathrm{p} 21^{\mathrm{WAF} 1}$ upregulation induced by vorinostat may be independent of p53 activity [31]. Importantly, Bcl-2 plays a crucial role regulating vorinostat-induced apoptosis in MM cells. Vorinostat does not trigger significant caspase activation; conversely, the pan-caspase inhibitor does not protect cells from vorinostat-induced cytotoxicity. Moreover, poly (ADP) ribose polymerase (PARP) is significantly cleaved by vorinostat, suggesting that vorinostat triggers caspaseindependent apoptosis in MM cells [31]. Vorinostat enhances the anti-MM activity of other therapeutic agents, 


\section{Potential Mechanisms of Action of HDAC Inhibitors in MM Treatment}

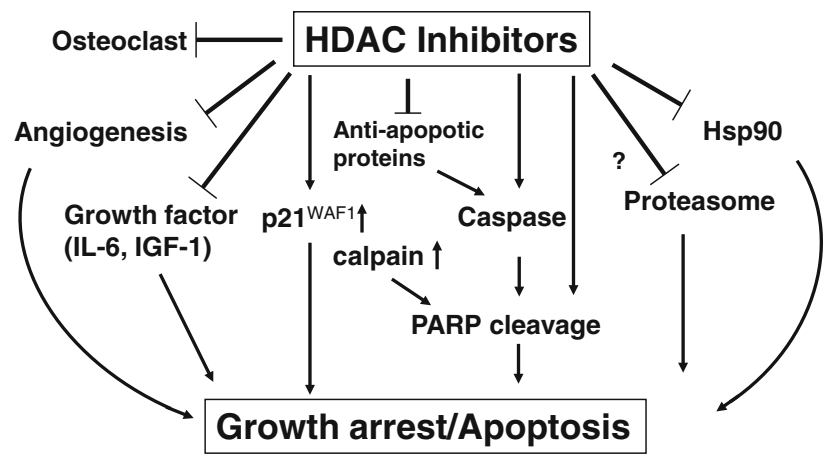

Fig. 2 Molecular mechanisms of action of HDAC inhibitors. HDAC inhibitors induce upregulation of $\mathrm{p} 21^{\mathrm{WAF} 1}$; trigger apoptosis via caspase-dependent and/or independent pathways; inhibit effects of growth factors (i.e., IL-6, IGF-1); inhibit angiogenesis; downregulate proteasome activity; and block osteoclastogenesis

including dexamethasone and immunomodulatory drugs (IMiDs). Importantly, vorinostat suppresses expression and activity of the proteasome and its subunits, providing the rationale for its use in combination with bortezomib to enhance its effect [5]. Vorinostat enhances tumor necrosis factor-related apoptosis-inducing ligand (TRAIL)-induced cytotoxicity associated with upregulation of the proapoptotic proteins (Bim, Bak, Bax, Noxa, and PUMA) and downregulation of anti-apoptotic proteins $(\mathrm{Bcl}-2$ and Bcl-xL) [32] (Fig. 2). Most recently, Chen et al. [33] reported that vorinostat blocks RAD51 protein response to ionizing radiation, thereby sensitizing MM cells to radiotherapy.

Among a number of HDAC inhibitor-based combination treatments, proteasome inhibitors show the most synergistic effects in MM in preclinical studies. Since both HDAC and proteasome inhibitors have complex mechanism of actions, even as single agent (Figs. 2, 3), the precise molecular mechanisms inducing MM cell growth inhibition by this combination is not yet completely defined. In these studies, non-selective HDAC inhibitors (vorinostat, panobinostat) combined with bortezomib trigger synergistic growth inhibitory effects and apoptosis in MM cells [13, 31]. Importantly, similar synergistic effects were observed with HDAC6-selective inhibitors (tubacin, ACY-1215) or HDAC knockdown combined with bortezomib, associated with a marked increase in polyubiquitinated proteins, followed by cell stress and apoptosis in both MM cell lines and patient MM cells. Since vorinostat and panobinostat also inhibit other HDAC isoforms, whether these synergistic cytotoxic effect triggered by non-selective HDAC inhibitors is solely due to their HDAC6 inhibitory effect is still unclear.

Although the synergistic effects of bortezomib with different classes of HDAC inhibitors have been observed in different settings, the conclusions made regarding the mechanisms of the synergy varied. This can be explained, at least in part, by differential potency and target proteins of various HDAC inhibitors. In addition, the pleiotropic effects that these agents elicit in MM cells, along with the experimental design of the individual studies, may have led the investigators to focus on the most relevant biological effects observed. The most well-characterized model to explain synergistic effect of proteasome inhibitors with HDAC inhibitors is through dual inhibition of the proteasomal and aggresomal protein degradation pathways [23, 26] (Fig. 4). Targeting both the proteasome and the aggresome by bortezomib and HDAC inhibitors, respectively, induces accumulation of polyubiquitinated proteins, resulting in increased cellular stress and apoptosis. More specifically, proteasome inhibition facilitates aggresome formation of polyubiquitinated proteins. Importantly, this process is dependent on the interaction of HDAC6 with tubulin and the dynein complex. Importantly, combined proteasome inhibitor with HDAC6 inhibitors leads to increased hyperacetylation of tubulin and upregulation of polyubiquitinated proteins, thereby increasing cellular stress response (i.e., endoplasmic reticulum stress) followed by apoptosis.

Other studies have proposed additional mechanisms. For example, it is possible that each agent affects complementary survival pathways in MM cells, thereby leading to synergistic effects on growth inhibition or cytotoxicity. Specifically, it was noted that exogenous overexpression of HDAC1 caused bortezomib resistance both in vitro and in vivo, which could be reversed by the class I HDAC inhibitor romidepsin. Moreover, bortezomib downregulates the expression of class I HDACs leading to histone hyperacetylation; thereby, enhancing HDAC inhibitorinduced cytotoxicity [34]. In addition, non-selective DAC inhibitor LAQ824 has been shown to decrease 20S proteasome activity [8]. The ability of proteasome inhibitors to downregulate HDACs, along with the observation that HDAC inhibitor can decrease proteasome activity, may contribute to the synergistic anti-tumor activities.

MM is characterized by infiltration of malignant plasma cells in the bone marrow (BM), and is associated with bone disease (osteolytic lesion). Specifically, bone formation depends on the balance of osteoblastogenesis and osteoclastogenesis. Importantly, a number of HDAC inhibitors suppress bone resorption by inhibiting osteoclasts in vitro and in animal models of chronic inflammatory diseases. Moreover, previous studies show that bortezomib enhances osteoblastogenesis, associated with Upregulation of Runx2 expression [35]. Therefore, combined HDAC inhibitors with bortezomib not only targets MM cells, but also could improve MM-associated bone disease. Indeed, combination treatment with a hydroxamate-based histone deacetylase 
Potential Anti-MM Activities of Proteasome Inhibitor in MM

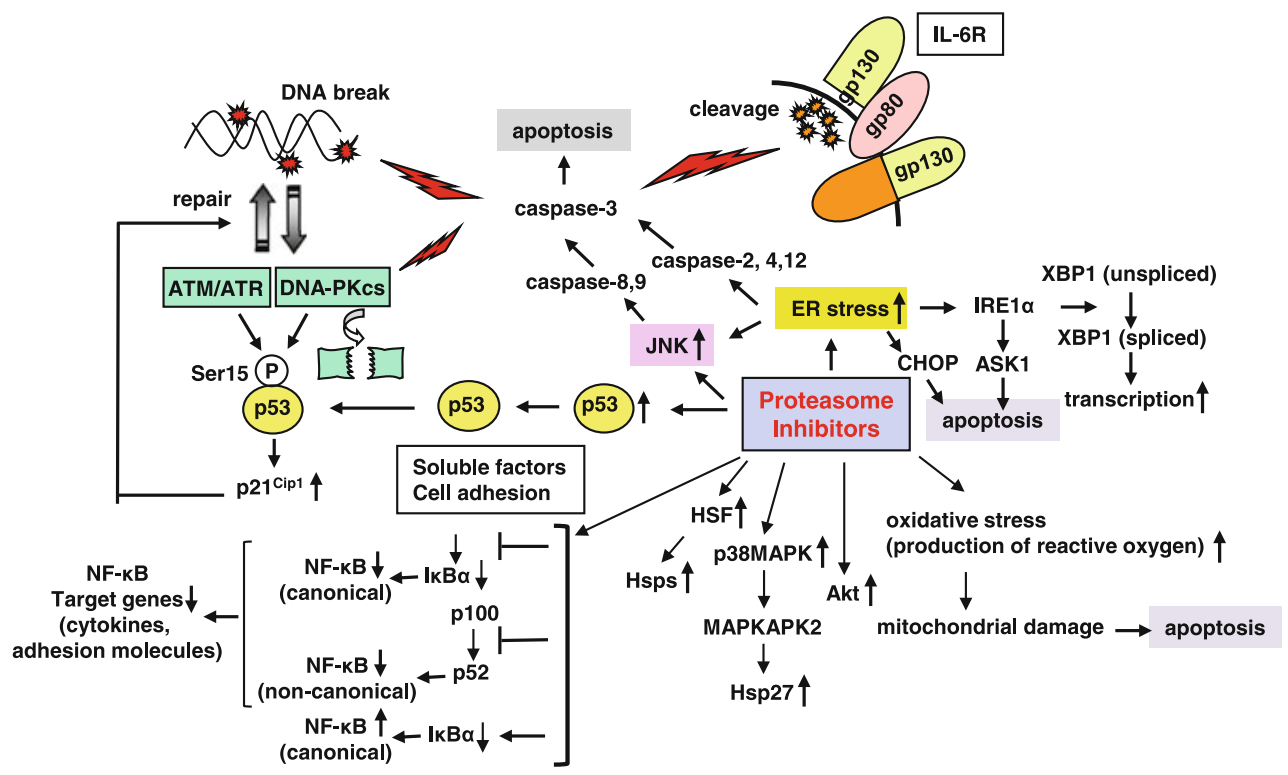

Hideshima T and Anderson KC, Seminar in Hematology 2012

Fig. 3 Mechanism of action of proteasome inhibitor-induced MM cell growth inhibition. Proteasome inhibitors upregulate p53 and induce JNK activation, followed by activation of caspases, which further triggers DNA damage (double-strand break) followed by activation of p53. Activated caspase-3 also cleaves DNA-PKcs and ATM/ATR, as well as gp130, resulting in impaired DNA repair and response to IL-6, respectively. Proteasome inhibitors trigger ER stress

inhibitor JNJ-26481585 and bortezomib shows a more pronounced decrease on tumor burden and MM bone disease in the 5T2MM model with reduction of osteoclasts and increase of osteoblasts, trabecular bone volume, and trabecular number compared with bortezomib monotherapy. This study therefore suggests that this combination therapy could be a useful strategy for the treatment of MM patients with skeletal complications [36]. Most recently, Santo et al. demonstrated the potential beneficial role of selective HDAC6 inhibition by ACY-1215 on MM-related bone disease in vitro and in vivo (Annual Meeting of American Society of Hematology, 2012, abstract 328).

\section{Clinical activities of HDAC inhibitors in MM}

Despite remarkable anti-MM activities of HDAC inhibitors in the preclinical setting, clinical utility of these agents is limited. Indeed, HDAC inhibitors showed only modest single agent activity in relapsed and refractory MM due to dose-limiting side effect profile, including fatigue, diarrhea, and thrombocytopenia. Based on remarkable preclinical anti-MM activity of HDAC inhibitors with bortezomib, ongoing HDAC inhibitor-based clinical trials in $\mathrm{MM}$ are conducted in combination with bortezomib (Table 3). and induce activation of IRE1 $\alpha$ followed by XBP1 splicing, thereby increasing its transcriptional activity. Proteasome inhibitors block inducible canonical NF- $\mathrm{NB}$ activity by cytokines/chemokines or cell adhesion. However, they can directly downregulate IKB $\alpha$ and canonical NF- $\kappa B$ activation, as well as non-canonical NF- $\kappa B$ activity by inhibiting proteasome-dependent $\mathrm{p} 100$ conversion to $\mathrm{p} 52$

Clinical trials of vorinostat in different type of malignancies have already been published [37-41]. In these studies, the maximum concentration of vorinostat in plasma $\left(C_{\max }\right)$ was $1631-1649 \mathrm{ng} / \mathrm{ml}$ and $2339-2963$ $\mathrm{ng} / \mathrm{ml}$ after 150 and $300 \mathrm{mg} / \mathrm{m}^{2}$ administration, respectively [37]. The maximum tolerated dose (MTD) of vorinostat in patients with solid tumors and hematologic malignancies treated with oral vorinostat was $400 \mathrm{mg} \mathrm{qd}$ and $200 \mathrm{mg}$ bid for continuous daily dosing, respectively, and $300 \mathrm{mg}$ bid for 3 consecutive days per week. The major dose-limiting toxicities (DLTs) were anorexia, dehydration, diarrhea, and fatigue [38]. In a phase I trial of single-agent vorinostat in patients with relapsed and/or refractory MM [41], only 1 patient $(7.7 \%)$ demonstrated a minimal response and 9 patients $(69.2 \%)$ demonstrated disease stabilization.

Clinical trials of romidepsine for different cancer types have also been reported [42-46]. In a phase I study, romidepsine was administrated by a 4-h i.v. infusion on days 1 and 5 of a 21-day cycle. The starting dose was $1 \mathrm{mg} / \mathrm{m}^{2}$, and dose escalations proceeded through a total of 8 dose levels to a maximum of $24.9 \mathrm{mg} / \mathrm{m}^{2}$. The MTD of romidepsine given on a day-1 and -5 schedule every 21 days is $17.8 \mathrm{mg} / \mathrm{m}^{2}$, with DLTs including fatigue, nausea, vomiting, transient thrombocytopenia, and neutropenia. Although cardiac toxicity was a potential concern based on preclinical data, there was no clinical toxicity 
Synergistic Anti-Tumor Activity by HDAC6 Inhibitors with Proteasome Inhibitors

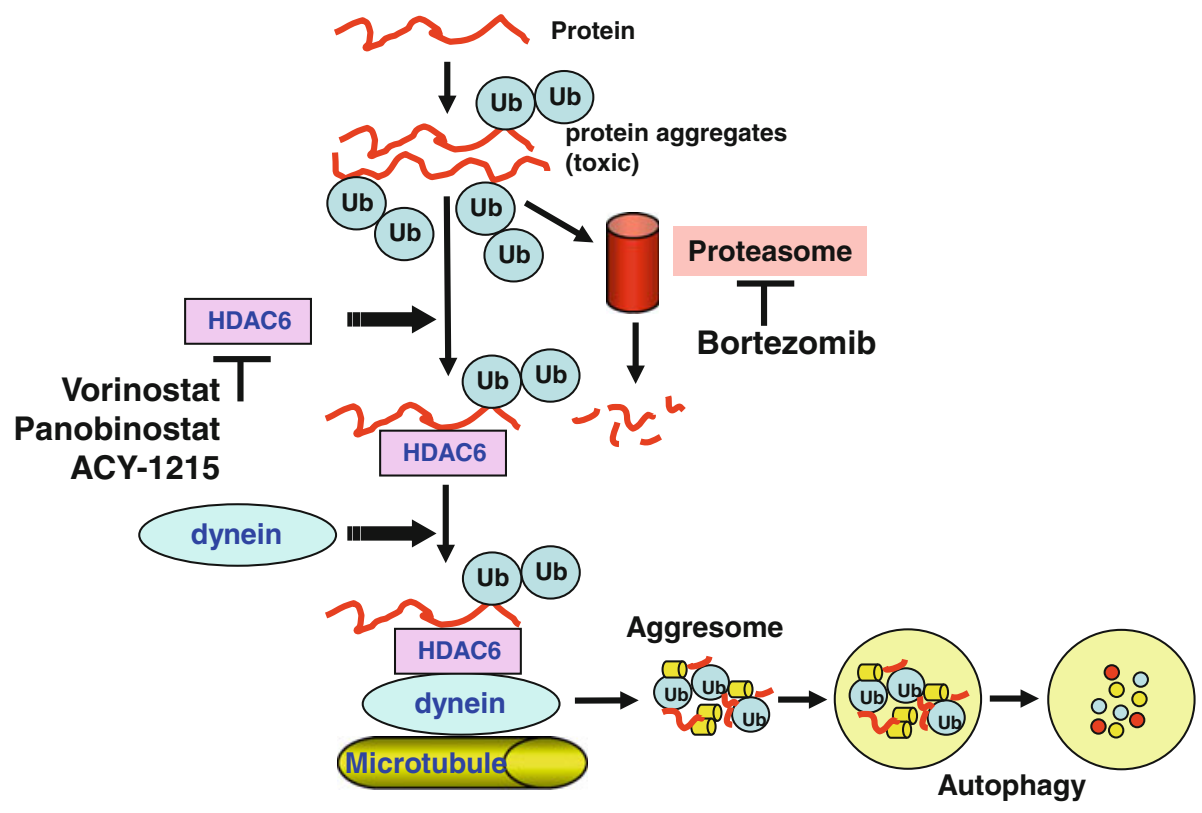

Fig. 4 Ubiquitinated protein catabolism in tumor cells and rationale for combination treatment of HDAC6 inhibitors with proteasome inhibitors. Misfolded proteins become polyubiquitinated and normally degraded by proteasomes. However, misfolded proteins can escape degradation due to abnormal or pathological conditions and form toxic aggregates. These misfolded and aggregated proteins are recognized and bound by HDAC6 through the presence of polyubiquitin chains. This allows for the loading of polyubiquitinated

Table 3 HDAC inhibitors in clinical trials in MM (selected)

\begin{tabular}{lll}
\hline HDACi & Combination & Phase \\
\hline 4SC-202 & & I \\
PCI-24781 & & I \\
JNJ26481585 & Bort. + Dex & I \\
Panobinostat & Everolimus (RAD001) & I/II \\
& Carfilzomib & I/Ib \\
& Bortezomib & I \\
Vorinostat & Len. + Dex & I \\
& Len. + Bort. + Dex & I \\
& Bort. + Doxil & I/II \\
& Len. + Dex & I/II \\
& Carfl. + Len. + Dex & I/II \\
& Bort. + DOX + Dex & I/II \\
& Mel. + Pred. & I/II \\
& Bort. & II \\
& Len. + Dex & II \\
& Bort. & II \\
& With Bort. or Bort. alone & III \\
\hline
\end{tabular}

Bold highlight indicates combo with proteasome inhibitor

[42]. In a phase II trial of single-agent romidepsine in 13 patients with refractory MM, there was evidence of disease stabilization and resolution of disease-related symptoms, misfolded protein cargo onto the dynein motor complex by HDAC6. The polyubiquitinated cargo-HDAC6-dynein motor complex then travels to the aggresome, where the misfolded and aggregated proteins are processed and degraded, clearing the cell of cytotoxic protein aggregates. Inhibition of both proteasomal and aggresomal protein degradation pathways by bortezomib and vorinostat/panobinostat/ACY-1215, respectively, induces endoplasmic reticulum stress, followed by synergistic cytotoxicity

although no objective responses were observed [47]. Overall, the activity of romidepsine as single agents has been limited, and a clearer understanding of the biological activity of these agents will help determine the ideal combination therapies for clinical development.

Panobinostat is currently most extensively studied in both preclinical studies and clinical trials in MM. In a phase Ib study of panobinostat with bortezomib, responses ( $\geq$ MR) were observed in $36 / 47(72 \%)$ of patients with relapsed or relapsed and refractory $\mathrm{MM}$. Based on these promising results, PANORAMA-1 study was initiated, a global randomized, double-blind, phase III study of panobinostat + bortezomib + dexamethasone vs placebo (PBO) + bortezomib + dexamethasone (San-Miguel J.F. et al. at the Annual Meeting of American Society of Clinical Oncology in 2011, abstract TPS227). In this study, patients $(n=672)$ with relapsed or relapsed and refractory MM (1-3 prior lines of therapy) will be enrolled. Prior bortezomib treatment is permitted; however, bortezomibrefractory MM patients are excluded.

PANORAMA-2 is a single-arm, phase II study of panobinostat + bortezomib + dexamethasone in patients with relapsed and bortezomib-refractory MM (Alsina et al. at the Annual Meeting of American Society of Clinical Oncology 2012, abstract 8012). This study has two 
treatment phases: phase 1 (TP1) consists of eight 3-week cycles of panobinostat + bortezomib + dexamethasone; patients who demonstrate clinical benefit enter treatment phase 2 (TP2), which consists of four 6-week cycles of panobinostat + bortezomib + dexamethasone. The primary endpoint is overall response [ $\geq$ partial response (PR)]. Fifty-five patients with bortezomib-refractory MM have been enrolled, with 10 patients ongoing and 28 in followup. Twenty-seven (49\%) and $36(65 \%)$ patients received bortezomib and dexamethasone in their most recent prior line of therapy, respectively. Eighteen patients achieved $\geq \mathrm{PR}$, for an overall response rate of $33 \%$ (1 near complete response and $17 \mathrm{PR}$ ); and 13 patients achieved MR, for a clinical benefit rate of $56 \%$. Three patients achieved a VGPR. Eighteen patients completed phase-1 and entered phase- 2 , and 2 have completed $\geq 12$ cycles. Common adverse events (AEs) of any grade included thrombocytopenia $(66 \%)$, fatigue (64\%), diarrhea (62\%), nausea (58\%), dyspnea (40\%), anemia (38\%), decreased appetite $(36 \%)$, and dizziness $(36 \%)$. Common grade 3/4 AEs included thrombocytopenia (58\%), fatigue (17\%), anemia (15\%), pneumonia (15\%), neutropenia (13\%), and diarrhea $(13 \%)$. Importantly, only 1 patient $(2 \%)$ experienced grade $3 / 4$ peripheral neuropathy.

Most recently, Richardson et al. also presented results of PANORAMA-2 study at the Annual Meeting of American Society of Hematology in 2012 (abstract 1852). In this presentation, 55 patients with bortezomib-refractory MM have been enrolled, and all patients were previously treated with bortezomib, dexamethasone, and at least 1 immunomodulatory drugs [lenalidomide (98\%), thalidomide (69\%)]. The overall response rate was $35 \%$ [1 near complete response and $18 \mathrm{PR}$ or better, with 3 patients achieving a very good partial response (VGPR)]. An additional 10 patients achieved MR, for a clinical benefit rate of $53 \%$. The median duration of exposure was 4.6 months. The median PFS and TTP were 4.9 months. The PFS for patients whose disease progressed on bortezomib $(n=39)$ and within 60 days of bortezomib ( $n=16$ ) was 4.2 and 7.6 months, respectively. In patients who achieved a response, the mean time to response was 1.7 months, and the median duration of response was 6.0 months.

A phase I/II study of ACY-1215 in relapsed/refractory MM patients was also reported by Raje et al. at the Annual Meeting of American Society of Hematology (2012, abstract 4061). In this study, 13 out of 16 patients were treated with ACY-1215 monotherapy and 3 patients were treated in combination with bortezomib. ACY-1215 monotherapy (up to $160 \mathrm{mg} /$ day) was well tolerated, with no DLTs and mostly grade 1-2 AEs. The most common AEs with monotherapy were elevated creatinine, diarrhea, fatigue, and upper respiratory tract infection ( $n=3$ each).
Grade 3/4 treatment-related AEs on monotherapy occurred in 1 patient (grade 3 anemia). In the first bortezomib combination cohort, 1 patient had a DLT (elevated amylase). Five monotherapy patients had stable disease, and one combination patient with relapsed/refractory disease had a $26 \%$ reduction of serum $M$ protein at Cycle 2 . These results suggest tolerability and potentiated efficacy of bortezomib with HDAC6 inhibitor in relapsed/refractory MM patients.

\section{Future directions}

A number of HDAC inhibitors have been developed and validated through histone hyperacetylation and/or enzymatic HDAC inhibition assays. The majority of these inhibitors nonselectively block HDAC isoforms and trigger significant antiMM activities. To reduce unfavorable side effects in patients, isoform-selective and/or class-selective HDAC inhibition is under evaluation. For example, a class I inhibitor entinostat and HDAC6-selective inhibitor ACY-1215 demonstrate significant MM cytotoxicity alone and/or in combination with bortezomib, indicating that non-selective HDAC inhibition is not required for this combination treatment.

The other important aspect of HDAC inhibitors is their activity on non-histone protein acetylation, thereby modulating their functions. Indeed, recent advanced technologies of proteomics reveal acetylation of a number of nonhistone proteins in cells treated with non-selective HDAC inhibitors. These studies indicate that HDAC inhibitors trigger cell growth inhibition by hyperacetylation not only of histones, but also of MM-relevant non-histone proteins including Hsp90, p53, STAT3, $\beta$-catenin, Sp1, c-Myc, Rel-A, PTEN and MDM2. To date, the effect of HDAC isoform-selective inhibitors on these non-histone proteins has not yet been determined.

Recently, compounds have combined two drugs into a single molecule with dual biologic effects. For example, CUDC-101 simultaneously inhibits histone deacetylase and the receptor kinases epidermal growth factor receptor and human epidermal growth factor receptor 2 in cancer cells and has great potential to improve sensitivity of heterogeneous and/or drug-resistant tumors [48]. Dual (multi)-targeted hybrid compounds, such as combination of proteasome and HDAC inhibitors may also have therapeutic efficacy in MM.

Conflict of interest The authors do not have conflict of interest.

\section{References}

1. Peterson CL, Laniel MA. Histones and histone modifications. Curr Biol CB. 2004;14:R546-51. 
2. Verdin E, Dequiedt F, Kasler HG. Class II histone deacetylases: versatile regulators. Trends Genet. 2003;19:286-93.

3. Minucci S, Pelicci PG. Histone deacetylase inhibitors and the promise of epigenetic (and more) treatments for cancer. Nat Rev Cancer. 2006;6:38-51.

4. Bradner JE, West N, Grachan ML, Greenberg EF, Haggarty SJ, Warnow T, Mazitschek R. Chemical phylogenetics of histone deacetylases. Nat Chem Biol. 2010;6:238-43.

5. Mitsiades CS, Mitsiades NS, McMullan CJ, Poulaki V, Shringarpure R, Hideshima T, Akiyama M, Chauhan D, Munshi N, Gu X, Bailey C, Joseph M, Libermann TA, Richon VM, Marks PA, Anderson KC. Transcriptional signature of histone deacetylase inhibition in multiple myeloma: biological and clinical implications. Proc Natl Acad Sci USA. 2004;101:540-5.

6. Remiszewski SW, Sambucetti LC, Bair KW, Bontempo J, Cesarz $\mathrm{D}$, Chandramouli N, Chen R, Cheung M, Cornell-Kennon S, Dean K, Diamantidis G, France D, Green MA, Howell KL, Kashi R, Kwon P, Lassota P, Martin MS, Mou Y, Perez LB, Sharma S, Smith T, Sorensen E, Taplin F, Trogani N, Versace R, Walker H, Weltchek-Engler S, Wood A, Wu A, Atadja P. N-Hydroxy-3phenyl-2-propenamides as novel inhibitors of human histone deacetylase with in vivo antitumor activity: discovery of (2E)- $N$ hydroxy-3-[4-[[(2-hydroxyethyl)[2-(1H-indol-3-yl)ethyl]amino]methyl]phenyl]-2-propenamide (NVP-LAQ824). J Med Chem. 2003;46:4609-24.

7. Atadja P, Gao L, Kwon P, Trogani N, Walker H, Hsu M, Yeleswarapu L, Chandramouli N, Perez L, Versace R, Wu A, Sambucetti L, Lassota P, Cohen D, Bair K, Wood A, Remiszewski S. Selective growth inhibition of tumor cells by a novel histone deacetylase inhibitor, NVP-LAQ824. Cancer Res. 2004;64: 689-95.

8. Catley L, Weisberg E, Tai YT, Atadja P, Remiszewski S, Hideshima T, Mitsiades N, Shringarpure R, LeBlanc R, Chauhan D, Munshi N, Schlossman R, Richardson P, Griffin J, Anderson KC. NVP-LAQ824 is a potent novel histone deacetylase inhibitor with significant activity against multiple myeloma. Blood. 2003;102: 2615-22.

9. George P, Bali P, Annavarapu S, Scuto A, Fiskus W, Guo F, Sigua C, Sondarva G, Moscinski L, Atadja P, Bhalla K. Combination of the histone deacetylase inhibitor LBH589 and the hsp90 inhibitor 17-AAG is highly active against human CML-BC cells and AML cells with activating mutation of FLT-3. Blood. 2005;105:1768-76.

10. Fiskus W, Pranpat M, Bali P, Balasis M, Kumaraswamy S, Boyapalle S, Rocha K, Wu J, Giles F, Manley PW, Atadja P, Bhalla K. Combined effects of novel tyrosine kinase inhibitor AMN107 and histone deacetylase inhibitor LBH589 against Bcr-Abl-expressing human leukemia cells. Blood. 2006;108:645-52.

11. Geng L, Cuneo KC, Fu A, Tu T, Atadja PW, Hallahan DE. Histone deacetylase (HDAC) inhibitor LBH589 increases duration of gamma-H2AX foci and confines HDAC4 to the cytoplasm in irradiated non-small cell lung cancer. Cancer Res. 2006;66: 11298-304.

12. Yu C, Friday BB, Lai JP, McCollum A, Atadja P, Roberts LR, Adjei AA. Abrogation of MAPK and Akt signaling by AEE788 synergistically potentiates histone deacetylase inhibitor-induced apoptosis through reactive oxygen species generation. Clin Cancer Res. 2007;13:1140-8.

13. Catley L, Weisberg E, Kiziltepe T, Tai YT, Hideshima T, Neri P, Tassone P, Atadja P, Chauhan D, Munshi NC, Anderson KC. Aggresome induction by proteasome inhibitor bortezomib and alpha-tubulin hyperacetylation by tubulin deacetylase (TDAC) inhibitor LBH589 are synergistic in myeloma cells. Blood. 2006;108:3441-9.

14. Maiso P, Carvajal-Vergara X, Ocio EM, Lopez-Perez R, Mateo G, Gutierrez N, Atadja P, Pandiella A, San Miguel JF. The histone deacetylase inhibitor LBH589 is a potent antimyeloma agent that overcomes drug resistance. Cancer Res. 2006;66: 5781-9.

15. Plumb JA, Finn PW, Williams RJ, Bandara MJ, Romero MR, Watkins CJ, La Thangue NB, Brown R. Pharmacodynamic response and inhibition of growth of human tumor xenografts by the novel histone deacetylase inhibitor PXD101. Mol Cancer Ther. 2003;2:721-8.

16. Qian DZ, Kato Y, Shabbeer S, Wei Y, Verheul HM, Salumbides B, Sanni T, Atadja P, Pili R. Targeting tumor angiogenesis with histone deacetylase inhibitors: the hydroxamic acid derivative LBH589. Clin Cancer Res. 2006;12:634-42.

17. Lucas DM, Davis ME, Parthun MR, Mone AP, Kitada S, Cunningham KD, Flax EL, Wickham J, Reed JC, Byrd JC, Grever MR. The histone deacetylase inhibitor MS-275 induces caspase-dependent apoptosis in B-cell chronic lymphocytic leukemia cells. Leukemia. 2004;18:1207-14.

18. Sakimura R, Tanaka K, Nakatani F, Matsunobu T, Li X, Hanada M, Okada T, Nakamura T, Matsumoto Y, Iwamoto Y. Antitumor effects of histone deacetylase inhibitor on Ewing's family tumors. Int J Cancer. 2005;116:784-92.

19. Konstantinopoulos PA, Vandoros GP, Papavassiliou AG. FK228 (depsipeptide): a HDAC inhibitor with pleiotropic antitumor activities. Cancer Chemother Pharmacol. 2006;58:711-5.

20. Kano Y, Akutsu M, Tsunoda S, Izumi T, Kobayashi H, Mano H, Furukawa Y. Cytotoxic effects of histone deacetylase inhibitor FK228 (depsipeptide, formally named FR901228) in combination with conventional anti-leukemia/lymphoma agents against human leukemia/lymphoma cell lines. Invest New Drugs. 2007;25: 31-40.

21. Karam JA, Fan J, Stanfield J, Richer E, Benaim EA, Frenkel E, Antich P, Sagalowsky AI, Mason RP, Hsieh JT. The use of histone deacetylase inhibitor FK228 and DNA hypomethylation agent 5-azacytidine in human bladder cancer therapy. Int $\mathrm{J}$ Cancer. 2007;120:1795-802.

22. Khan SB, Maududi T, Barton K, Ayers J, Alkan S. Analysis of histone deacetylase inhibitor, depsipeptide (FR901228), effect on multiple myeloma. Br J Haematol. 2004;125:156-61.

23. Santo L, Hideshima T, Kung AL, Tseng JC, Tamang D, Yang M, Jarpe M, van Duzer JH, Mazitschek R, Ogier WC, Cirstea D, Rodig S, Eda H, Scullen T, Canavese M, Bradner J, Anderson KC, Jones SS, Raje N. Preclinical activity, pharmacodynamic, and pharmacokinetic properties of a selective HDAC6 inhibitor, ACY-1215, in combination with bortezomib in multiple myeloma. Blood. 2012;119:2579-89.

24. Kawaguchi Y, Kovacs JJ, McLaurin A, Vance JM, Ito A, Yao TP. The deacetylase HDAC6 regulates aggresome formation and cell viability in response to misfolded protein stress. Cell. 2003;115: 727-38.

25. Garcia-Mata R, Gao YS, Sztul E. Hassles with taking out the garbage: aggravating aggresomes. Traffic. 2002;3:388-96.

26. Hideshima T, Bradner JE, Wong J, Chauhan D, Richardson P, Schreiber SL, Anderson KC. Small-molecule inhibition of proteasome and aggresome function induces synergistic antitumor activity in multiple myeloma. Proc Natl Acad Sci USA. 2005; 102:8567-72.

27. Feng R, Hager JH, Hassig CA, Scranton SA, Payne JE, Mapara MY, Roodman D, Lentzsch S. A novel, mercaptoketone-based HDAC inhibitor, KD5170 exerts marked inhibition of osteoclast formation and anti-myeloma activity in vitro. Blood. 2006;108: 991a.

28. Piekarz R, Bates S. A review of depsipeptide and other histone deacetylase inhibitors in clinical trials. Curr Pharm Des. 2004;10: 2289-98.

29. Loprevite M, Tiseo M, Grossi F, Scolaro T, Semino C, Pandolfi A, Favoni R, Ardizzoni A. In vitro study of CI-994, a histone 
deacetylase inhibitor, in non-small cell lung cancer cell lines. Oncol Res. 2005;15:39-48.

30. Choudhary C, Kumar C, Gnad F, Nielsen ML, Rehman M, Walther TC, Olsen JV, Mann M. Lysine acetylation targets protein complexes and co-regulates major cellular functions. Science. 2009;325:834-40.

31. Mitsiades N, Mitsiades CS, Richardson PG, McMullan C, Poulaki V, Fanourakis G, Schlossman R, Chauhan D, Munshi NC, Hideshima T, Richon VM, Marks PA, Anderson KC. Molecular sequelae of histone deacetylase inhibition in human malignant $\mathrm{B}$ cells. Blood. 2003;101:4055-62.

32. Fandy TE, Shankar S, Ross DD, Sausville E, Srivastava RK. Interactive effects of HDAC inhibitors and TRAIL on apoptosis are associated with changes in mitochondrial functions and expressions of cell cycle regulatory genes in multiple myeloma. Neoplasia. 2005;7:646-57.

33. Chen X, Wong P, Radany EH, Stark JM, Laulier C, Wong JY. Suberoylanilide hydroxamic acid as a radiosensitizer through modulation of RAD51 protein and inhibition of homologydirected repair in multiple myeloma. Mol Cancer Res. 2012;10: 1052-64.

34. Kikuchi J, Wada T, Shimizu R, Izumi T, Akutsu M, Mitsunaga K, Noborio-Hatano K, Nobuyoshi M, Ozawa K, Kano Y, Furukawa Y. Histone deacetylases are critical targets of bortezomib-induced cytotoxicity in multiple myeloma. Blood. 2010;116:406-17.

35. Mukherjee S, Raje N, Schoonmaker JA, Liu JC, Hideshima T, Wein MN, Jones DC, Vallet S, Bouxsein ML, Pozzi S, Chhetri S, Seo YD, Aronson JP, Patel C, Fulciniti M, Purton LE, Glimcher LH, Lian JB, Stein G, Anderson KC, Scadden DT. Pharmacologic targeting of a stem/progenitor population in vivo is associated with enhanced bone regeneration in mice. J Clin Invest. 2008;118:491-504.

36. Deleu S, Lemaire M, Arts J, Menu E, Van Valckenborgh E, Vande Broek I, De Raeve H, Coulton L, Van Camp B, Croucher $\mathrm{P}$, Vanderkerken K. Bortezomib alone or in combination with the histone deacetylase inhibitor JNJ-26481585: effect on myeloma bone disease in the 5T2MM murine model of myeloma. Cancer Res. 2009;69:5307-11.

37. Kelly WK, Richon VM, O'Connor O, Curley T, MacGregorCurtelli B, Tong W, Klang M, Schwartz L, Richardson S, Rosa E, Drobnjak M, Cordon-Cordo C, Chiao JH, Rifkind R, Marks PA, Scher H. Phase I clinical trial of histone deacetylase inhibitor: suberoylanilide hydroxamic acid administered intravenously. Clin Cancer Res. 2003;9:3578-88.

38. Kelly WK, O'Connor OA, Krug LM, Chiao JH, Heaney M, Curley T, MacGregore-Cortelli B, Tong W, Secrist JP, Schwartz L, Richardson S, Chu E, Olgac S, Marks PA, Scher H, Richon VM. Phase I study of an oral histone deacetylase inhibitor, suberoylanilide hydroxamic acid, in patients with advanced cancer. J Clin Oncol. 2005;23:3923-31.
39. Krug LM, Curley T, Schwartz L, Richardson S, Marks P, Chiao J, Kelly WK. Potential role of histone deacetylase inhibitors in mesothelioma: clinical experience with suberoylanilide hydroxamic acid. Clin Lung Cancer. 2006;7:257-61.

40. Duvic M, Talpur R, Ni X, Zhang C, Hazarika P, Kelly C, Chiao JH, Reilly JF, Ricker JL, Richon VM, Frankel SR. Phase 2 trial of oral vorinostat (suberoylanilide hydroxamic acid, SAHA) for refractory cutaneous T-cell lymphoma (CTCL). Blood. 2007; 109:31-9.

41. Richardson P, Mitsiades C, Colson K, Reilly E, McBride L, Chiao J, Sun L, Ricker J, Rizvi S, Oerth C, Atkins B, Fearen I, Anderson K, Siegel D. Phase I trial of oral vorinostat (suberoylanilide hydroxamic acid, SAHA) in patients with advanced multiple myeloma. Leuk Lymphoma. 2008;49:502-7.

42. Sandor V, Bakke S, Robey RW, Kang MH, Blagosklonny MV, Bender J, Brooks R, Piekarz RL, Tucker E, Figg WD, Chan KK, Goldspiel B, Fojo AT, Balcerzak SP, Bates SE. Phase I trial of the histone deacetylase inhibitor, depsipeptide (FR901228, NSC 630176), in patients with refractory neoplasms. Clin Cancer Res. 2002;8:718-28.

43. Marshall JL, Rizvi N, Kauh J, Dahut W, Figuera M, Kang MH, Figg WD, Wainer I, Chaissang C, Li MZ, Hawkins MJ. A phase I trial of depsipeptide (FR901228) in patients with advanced cancer. J Exp Ther Oncol. 2002;2:325-32.

44. Byrd JC, Marcucci G, Parthun MR, Xiao JJ, Klisovic RB, Moran M, Lin TS, Liu S, Sklenar AR, Davis ME, Lucas DM, Fischer B, Shank R, Tejaswi SL, Binkley P, Wright J, Chan KK, Grever MR. A phase 1 and pharmacodynamic study of depsipeptide (FK228) in chronic lymphocytic leukemia and acute myeloid leukemia. Blood. 2005;105:959-67.

45. Robey RW, Zhan Z, Piekarz RL, Kayastha GL, Fojo T, Bates SE. Increased MDR1 expression in normal and malignant peripheral blood mononuclear cells obtained from patients receiving depsipeptide (FR901228, FK228, NSC630176). Clin Cancer Res. 2006; 12:1547-55.

46. Stadler WM, Margolin K, Ferber S, McCulloch W, Thompson JA. A phase II study of depsipeptide in refractory metastatic renal cell cancer. Clin Genitourin Cancer. 2006;5:57-60.

47. Niesvizky R, Ely S, Mark T, Aggarwal S, Gabrilove JL, Wright JJ, Chen-Kiang S, Sparano JA. Phase 2 trial of the histone deacetylase inhibitor romidepsin for the treatment of refractory multiple myeloma. Cancer. 2011;117:336-42.

48. Lai CJ, Bao R, Tao X, Wang J, Atoyan R, Qu H, Wang DG, Yin L, Samson M, Forrester J, Zifcak B, Xu GX, DellaRocca S, Zhai HX, Cai X, Munger WE, Keegan M, Pepicelli CV, Qian C. CUDC-101, a multitargeted inhibitor of histone deacetylase, epidermal growth factor receptor, and human epidermal growth factor receptor 2, exerts potent anticancer activity. Cancer Res. 2010;70:3647-56. 